\title{
What's the tally? An Investigation into the Field(s) of Dominant Designs and Platforms
}

\author{
Vladimir C. M. Sobota \\ TU Delft \\ v.c.m.sobota@tudelft.nl
}

\author{
Roland J. Ortt \\ TU Delft \\ j.r.ortt@tudelft.nl
}

\author{
Geerten van de Kaa \\ TU Delft \\ g.vandekaa@tudelft.nl
}

\author{
Cees van Beers \\ TU Delft \\ c.p.vanbeers@tudelft.nl
}

\begin{abstract}
Dominant designs and platforms are two distinct scientific fields in the analysis of innovation of and competition between technologies. Responding to calls for more synthesis in management research, we study the commonalities and differences between the fields surrounding these concepts. To this end, we develop a framework for the comparison of concepts and apply it to dominant designs and platforms. We show that dominant designs and platforms differ most prominently regarding their central mechanisms, their unit and level of analysis, and the timeframe. We will elaborate how they are complementary by developing a research agenda.
\end{abstract}

\section{Introduction}

Dominant designs and platforms define complex technological infrastructures and are linked to distinct approaches in studying technological innovation and competition. In current days, the term platform enjoys great popularity among scholars and practitioners [e.g., $1,2,3]$. Dominant designs [4, 5] had their bloom earlier $[6,7]$, eking out a niche existence in current days.

Platforms are meta-organizations that orchestrate loosely coupled parties and facilitate economies of scale and scope [1]. Dominant designs are persistent architectures that define core design concepts [8]. Despite their lagged development, there is good reason to assume that dominant designs and platforms as concepts are at least complementary. Both deal with technological innovation that is broadly applicable and used by different actors for different purposes. These technological innovations are mostly not stand-alone - many actors must come together to create a solution that works reasonably well across different application domains. The requirements of these domains change over time, and so do the technological innovations. In studying such innovations, the field of platforms focuses on purposefully aligning loosely coupled actors that contribute complementary products and services towards a central value proposition. The field of dominant designs takes an evolutionary perspective in which coordination is achieved through settling on a value proposition's core design specifications. These are developed by trial and error in different application domains.

With interest in complementarities at the intersection of both fields, we first answer the following question: What are the systematic differences and commonalities between dominant designs and platforms? To answer this question, we sketch the fields' development, construct a review framework to systematically compare the fields, and elaborate the differences and commonalities. We then integrate the fields and propose directions for future research.

We find that platforms research focusses on platform-internal coordination and competition between platforms and does not explain why platforms emerge. Dominant designs thinking focusses on the successive dominance of designs, dubbed technology cycle. We integrate these differences into a research agenda that addresses platform design and management against the context of evolutionary mechanisms on various levels of analysis.

Except for occasional reference to their similarity [2, 9], we believe that the question of our paper is unanswered, yet very relevant. Managers and scholars of technological innovation deal with innovations and systems that are not stand-alone, subjected to change over time, and catering to different application domains, corresponding to the phenomena studied by the fields of platforms and dominant designs. While this applies to information and communication technologies in as much as to diesel engines, we think that the field of information systems (IS) with open and generative systems is particularly exposed to such systems.

\section{Development of the literature}

Dominant designs research emerged from scholarly interest in the interaction between organization and environment [10]. In the 1960s, some economists argued 
that one had to look at the inner workings of technologies and not only at their performance characteristics in order to understand economic change [11]. Scholars such as Abernathy, Utterback, and Rosenberg were among the first who worked on the opening of the 'black box' of technology. Dominant design thinking is rooted in the observation that technology progresses are based on trial and error. When a new product class emerges, the technology's inherent potential and its anticipated users' needs are unknown. Creating different designs and introducing them to the market is the only way to reduce uncertainty [12], next to the involvement of users in the design process [13]. The term dominant design was first mentioned by Abernathy and Utterback. A dominant design is a specific design of a technological innovation that is found to be relatively good across a variety of applications and hence is adopted by a large portion of the customers. With the emergence of a dominant design, a shift from radical to incremental product innovation with more intense price competition and an increased focus on process innovation starts. However, this phase can have a limited life - it can be disturbed by a so-called technology shock, which evolutionary economists define as another technology that substantially increases production output [14]. Tushman and Anderson [10] distinguish two types of technological discontinuities: competence-destroying and competence-enhancing discontinuities. The former is so essentially different from previously dominant technologies that previously essential knowledge is no longer viable. The latter refer to order of magnitude improvements in performance or price which still build on the previously viable knowledge.

Based on this thought, Anderson and Tushman [6] define the technology cycle which is launched by introducing a technological discontinuity. Thereafter, a somewhat chaotic phase emerges in which actors try to build up a system around alternative new technologies while, at the same time, these technologies do compete with each other and the previous dominant technology. In this phase, the number of technology variations in product class increases, and this phase is referred to as the era of ferment. This stage is followed by dominant design selection and an era of incremental change, which continues until the status quo is disrupted by another technological discontinuity. Empirical studies have focused on dominant designs with respect to entry and exit patterns [15, 16, 17], firm founding and exits [18], and entry with respect to the technology cycle [7], amongst others. Strategy scholars were interested in strategies for creating dominant designs.

Platforms research has its roots in network economics - the studying of industries in which a technology's value is conditional on the number of other users of the same technology [19, 20]. Telephones, email, mobile phones are examples of pure network technologies, i.e., technologies which have close to no standalone value [21]. The sum of all users at any given moment is called installed base. Network technologies can have specific characteristics such as path dependence, which means that current design characteristics may depend on somewhat accidental past events yet, once established, are difficult to change. For example, David [22] argued that today's QWERTY keyboard layout can be traced back to design decisions that may have seemed unremarkable at the time. Due to the installed base, firms are kept off from making major discontinuous design changes. In a formal model, Arthur [23] shows how initial minor design choices are cemented over time. Path dependence often results in positive feedback loops, both increasing leads and accelerating declines [24]. If positive feedback is strong enough, the market may show winnertake-all characteristics.

Since the early start of this millennium, industrial economy scholars have started paying attention to platforms, conceptualized as 'two-sided markets', [25] 'multi-sided markets' [26], or 'multi-sided platforms' [27]. Scholars view platforms as intermediaries that facilitate the interaction between different groups, or socalled sides of a market. Rochet and Tirole [25] capture two-sided markets in a theoretical model as a mixture of network economics and multi-product pricing that stresses cross-elasticities. Central to this literature is that various platforms compete against each other. The premise is that users value a platform more the larger its number of users is. Next to direct (or same side) network effects, two-sided markets are also driven by indirect network effects. These occur if "the benefit to users in at least one group (side A) depends on the number of other users in the other group (side B). An indirect network effect arises if there are cross-group network effects in both directions (from A to B and from B to A) and side B's participation decision depends on the number of participants on side A so that the benefit to a user on side $B$ depends (indirectly) on the number of users on side A" [28:5]. Together, both mechanisms can cause the emergence and prevalence of a dominant platform to the platform leader's advantage [29] (dominant platforms are also dubbed focal platforms [30] or established platforms [31]). Frequently studied topics are getting "both sides on board" [25:990] while avoiding the “chicken and egg-problem” [32]. Often, these problems are addressed through pricing and subsidizing one side in order to attract the other [25, 33, 34].

Meanwhile, organizational theorists studied platforms as technological architectures that help to manage complexities [1]. Wheelwright and Clark [35] were the first to explicitly mention the term platform, referring to products that address core customers' wants but can be 
adapted by adding or removing features. This perspective's broader theme became the systematic reusing of components which facilitated economics of scope in production and innovation. Engineering platforms were observed to entail a modular technological architecture as a commonality [36]. Baldwin and Woodard also introduce the idea of a stable core and a more variable periphery as characteristics of platforms, highlighting the facilitation of innovation as a key function of platforms. Empirical studies have focused on platforms across firms in supply chains [e.g., 37, 38, 39] but also in more extensive networks of firms that are not linked through supply chains, called innovation ecosystems or platform ecosystems [e.g., 40, 41, 42]. Reviewing both streams, Gawer [1] suggested a overarching definition, characterizing platforms as (meta) organizations that federate actors, have a modular architecture consisting of a core and a periphery, and facilitate economies of scale and scope.

\section{Methodology}

To compare the literatures on dominant designs and platforms, we (1) selected papers that are representative of their respective field, (2) developed a review framework, and (3) qualitatively coded the papers based on this framework.

First, we created a sample of studies by searching for dominant designs and platforms (including synonyms) on ISI Web of Science. To identify studies that belong to the field's core, we proceeded with the top 500 mostcited papers. We checked the resulting papers for substantial fit, removing purely technical papers and those that treat platforms and dominant designs only in passing. Since an absolute citation measure has its downsides (e.g., favors older papers, does not account for different citation patterns across disciplines and time [43]), we supplemented the sample with papers in the Web of Science 'highly cited paper' category. The 'highly cited' indicator takes different citation rates by field and paper age into account [44], addressing some of the problems of citation numbers as a quality proxy. Based on this sample, we create citation, co-citation, and bibliographic coupling maps with the software VOSviewer (www.vosviewer.com) to select key papers.

Second, we developed a review framework to conceptually analyze and distinguish between dominant designs and platforms. It consists of two major parts, called positioning (Figure 1, top) and distinguishing features (Figure 1, bottom). We now discuss both in more detail.

Distinguishing features forms the framework's core and is based on an cause-mechanism-output framework, inspired by similar studies that have used this structure to define concepts $[45,46,47]$. It contains the aspects cause, mechanism, contrast, complementary aspects, and outcome. Each of these aspects can be used (alone or in combination) to define a concept. For example, a natural disaster is defined as "a sudden and terrible event in nature (such as a hurricane, tornado, or flood) that usually results in serious damage and many deaths" [48]. Here, the outcome is destruction and death, and the cause is a terrible event in nature. This definition draws on the aspects cause and output, but does not draw on the aspects mechanism, contrast, or complementary aspects, so that these are left void. Complementary aspects and contrast may require more explanation. Definition by complementary aspects refers to specification of a concept's complementary components. For example, communication appliances can be defined as appliances that require an infrastructure. Clarification by contrast relates to discriminant validity which ensures that one construct can be empirically distinguished from similar constructs and that aspects unrelated to the construct can be indicated [49].

What we summarize under positioning is related to the boundaries based on assumptions that constrain theory [49]. It is implicitly evident that contextual factors [e.g., 50], and the disciplinary background [e.g., 1, 51] are used to structure reviews. Therefore, we divide positioning into the aspects perspective, discipline, and context (see Figure 1).

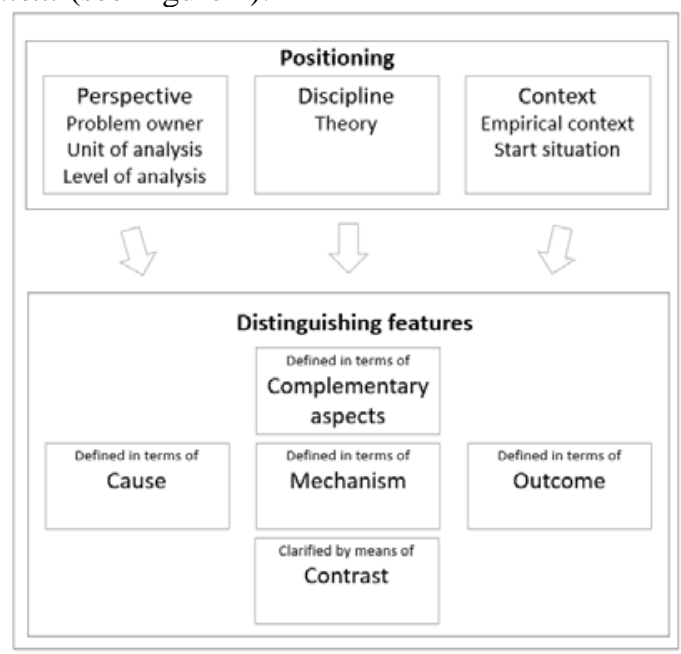

Figure 1. Review framework

Third, we analyzed relevant papers based on the framework in a qualitative way. As a first step, the first and third authors assigned papers to the streams of dominant designs and platforms. Cases of disagreement were solved via discussion. To judge a paper's positioning, we used the following guidelines. A research paper's perspective is judged based on the problem owner of the research problem, the unit of analysis, and the level of analysis. The problem owner and the role are inferred from the practical implications presented in the 
paper. The level of analysis concerns the level or granularity of the research, whereas the unit of analysis refers to the entity or actor that is studied [52]. Both unit and level of analysis are used in other frameworks to structure literature reviews, e.g., [53]. Often, the disciplinary background is explicitly mentioned, for example in Gawer's [1] review covering the engineering and economics perspective on platforms, as already mentioned in the abstract. In other cases, we preferably infer this information from the theory used in the article due to the field's interdisciplinary nature. The analysis of distinguishing features started by analyzing definitions of the key concepts dominant designs and platforms. Only after extracting information from the definitions (if present) did we look at the remainder of the paper.

\section{Analytical results}

Table 1 presents the outcome of the analysis of key papers in condensed form with respect to the framework presented above.

\subsection{Analysis of Distinguishing features}

4.1.1. Analysis of causes. The analysis of causes of dominant design selection revealed no consensus in the literature. According to Abernathy and Utterback [4], users are assumed to play a major role in the selection of a dominant design as their understanding of performance requirement is more intimate, leading them to make 'suggestions' with respect to the consequent version of that innovation. As this research is framed from the perspective of firms (and seemingly dissociate from consumers), suggestions by users likely take the form of purchase decisions. This, in turn, would imply that dominant design selection is installed-base driven. Anderson and Tushman [6] argue that dominant designs emerge from radical innovation as a consequence of efforts by manufacturers, customers, suppliers, and regulators to decrease uncertainty, which is common with many of the reviewed studies. Furthermore, market demand, market power by leading producers, and first mover advantage are mentioned as possible causes of a dominant design [6], as well as various economic and organizational factors, such as the possession of collateral assets, industry regulation, government intervention or managerial strategic action [15]. Constant [54], in his description of the jet-powered airplane, maintains that the dominant design, although not optimal in specific applications, was the design with the best performance across a wide variety of applications. Schilling [55] writes that dominant designs emerge in situations of extreme path dependency. Gallagher [8] suggests that dominant designs are triggered by radical innovation.

In contrast, many seminal papers offer no cause that triggers the emergence of a platform [25, 40, 50]. For engineering platforms, Gawer's [1] review suggests complexity as a condition for modularity. Hence, complexity could be seen as a condition for platforms to arise. The economics perspective on (multi-sided) platforms assumes the pre-existence of different sides with a need for interaction that the platform facilitates in the form of a conduit, presumably lowering transaction costs. Recent advances in ecosystem theory, although different from the economics perspective, suggest that ecosystems emerge in response to a "need for coordination that cannot be dealt with in markets", enabled by a modular design [51:2260]. These examples, however, create the impression of necessary conditions rather than sufficient conditions for platform emergence, which is no surprise as platforms come into existence based on managerial action [9].

Key distinction: Neither of the streams has settled on what causes their phenomenon to emerge. In both dominant design research and the economic perspective on platforms, installed base plays a role as a cause. Radical innovation is only mentioned with respect to dominant designs. Contrarily, platforms do not simply emerge without firm-level agency [9]. That means that platforms are deliberately created by firms in contrast to dominant designs that emerge in the market because of the collective action of many firms and other actors. In both streams, complexity plays a role. Modularity as a condition is mentioned only in platforms research.

Table 1. Commonalities and differences between dominant designs and platforms

\begin{tabular}{lll}
\hline & Dominant Designs & Platforms \\
\hline Definition & $\begin{array}{l}\text { Prevalent architectures that define a set of core design } \\
\text { concepts } \\
\text { Discipline }\end{array}$ & $\begin{array}{l}\text { (Meta) organizations facilitating economies of scale and } \\
\text { scope, modular architecture } \\
\text { (Evolutionary) economics, (innovation) management }\end{array}$ \\
Problem owner & Manager & Platform leader, manager \\
Unit of Analysis & Technological design architecture & Meta-organization, platform, ecosystem \\
Level of analysis & Industry, product class & Ecosystem, product family, central value proposition \\
Context & High-tech manufacturing (e.g., automotive) / ICT & ICT / consumer electronics \\
Start situation & Alternative / competing technological design & Unspecified \\
Cause & Radical innovation & largely unspecified \\
Mechanism & Emergent, demand-driven competition, sometimes & (Indirect) network effects, pricing, ecosystem governance, \\
& network effects, learning effects & asset specificity
\end{tabular}




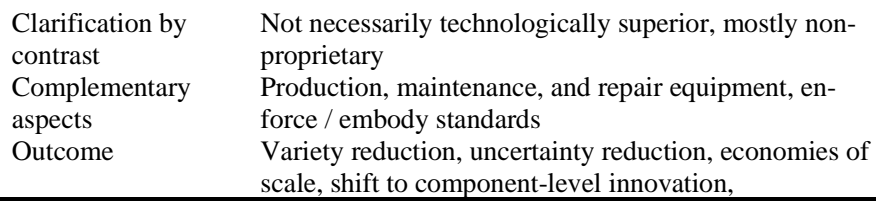

Ecosystems: not fully hierarchically controlled

Modular architecture, composed of core and periphery, complementary products and services that utilize the core Value co-creation, intermediation
4.1.2. Analysis of mechanisms. The selection process of a dominant design is described as emergent [56] or evolutionary [57]. Abernathy and Utterback [4] give no information about the mechanism's operational mode. Suarez and Utterback [15] emphasize that technological factors alone may not suffice to explain dominant design selection, as the dominant design is not necessarily the design with the highest technological performance. Bandwagon effects and network may also play a role. Anderson and Tushman [6] are not very specific with regard to the mechanism behind dominant design selection - they describe it as emergent from demand-driven competition. Also, here, it is implied that dominant design selection is installed-base driven. That means that the design with the largest installed base is selected as the dominant design. The introduction of the technology cycle makes an essential point regarding the duration of mechanisms, suggesting that it is a recurring and ongoing process. Schilling [55] posits that increasing returns to adoption, pressure for compatibility, and government regulation may lead to the selection of a dominant design. Network effects, however, are not necessary for the emergence of a dominant design [8]. A design can be selected as the dominant design simply because it is the better product, scoring higher on the price-performance-ratio.

The mechanisms of platforms, on the other hand, have received much more attention. Fascinated by the prospect of monopoly profits, much research addressed how the dominance of platforms. Van Alstyne et al. [58] write that network effects drive platforms' power and success. Dominance aside, platforms (and their ecosystems) have been contrasted based on internal coordination mechanisms. As shown in section 4.1.1., a need for coordination that exceeds the potential of markets is a condition for platforms to arise. Gawer [1] calls this coordination mechanism 'ecosystem governance' which is done based on pricing in the case of multi-sided platforms, however, without specifying what it would entail otherwise. In comparison with other network forms, Jacobides et al. [51] stress that ecosystems are not fully hierarchically controlled, meaning that ecosystems must rely on control mechanisms other than managerial hierarchy. Ecosystems are bound together by the characteristic that the collective investment cannot be recovered or redeployed elsewhere.

The provision of tools and resources, or the re-use of components is an often-mentioned feature of platforms that can be placed between dominance-related mechanisms and internal coordination mechanisms [e.g., 1, 59, 60]. The systematic re-use of components allows for economies of scope in production. Economies of scope are present when the joint production of goods is cheaper than the individual production of goods [61].

Key distinctions. The analysis shows that, in the field of platforms, two types of mechanisms are analyzed: Mechanisms leading to the dominance of platforms, and on the other hand, internal coordination mechanisms. Platforms and dominant designs, hence, relate differently to the notion of dominance. There is scope for a platform in the absence of dominance (in fact, this is how many platforms have grown, e.g., Facebook in its early days) as it can successfully and persistently serve a niche, and several platforms can exist next to each other, see the video game console market. Here lies a key difference with a dominant design which "is simply one among many different 'design approaches'” [8:272] in the absence of dominance. Furthermore, the common denominator regarding the mechanism behind dominant design selection is that it is demand-driven, while some authors describe it as evolutionary or do not reference to mechanisms at all. This contrasts with research platforms where mechanisms have received much attention. With dominant designs, coordination occurs by settling on a dominant design, meaning by choice of technology alone. Besides, dominant design selection mechanisms cover different tie spans - selection is recurring or ongoing, whereas platforms' mechanisms potentially lead to the prevalence of one dominant platform. The idea that different platforms may take their turns in being dominant has not been described.

4.1.3. Analysis of outcomes and complementary aspects. Many dominant design studies define dominant designs as an outcome. Abernathy and Utterback [4] describe innovation patterns ajar empirical observations in the semiconductors, aircraft, electronics, and automotive industries. The development of a dominant design is seen as "the shift from radical to evolutionary product innovation" [4:6]. This means that a state of evolutionary product innovation is reached once the development of a dominant design is concluded. This early concept of a dominant design is common with many other studies, some of which characterize a dominant design as reducing variation and uncertainty in a product class [6], or the shift of technology development at the component and process level [7]. Another frequently mentioned 
outcome is economies of scale by enforcing standardization $[6,15]$. This causal chain, however, is not shared by all studies - even though still defined as the outcome, Henderson and Clark [56] see a dominant design as emergent from the opportunity to obtain economies of scale (with reference to David [22] and Arthur [23]). Constant [54] claims that dominant designs also emerge as result of economies of scope because he describes the design as the best compromise in a range of applications. Apart from that, this article lays the foundation of many other views on dominant designs by introducing architectural innovation and by defining a dominant design in this light. Here, a dominant design manifests in the stabilization of architectural knowledge which then becomes encoded and implicit. Architectural knowledge concerns the links between components rather than the components themselves [56:11]. An architectural innovation alters how a product's components are related to each other without affecting the knowledge underlying the components [56:10]. The idea of architectural knowledge takes a central place in later studies, such as Christensen et al. [7] who operationalize dominant designs based on architectural configurations, or Gallagher [8:374] who portrays dominant designs as "persistent architectures". The emergence of such a persistent architecture usually accompanied by a convergence of design attributes [8].

Whereas dominant designs are often defined as an outcome, platforms research frequently draws on both outcome and complementary aspects to define the central concept. A notable definition in this respect is the one by Van Alstyne et al. [58] who explicitly mention platform owner, platform provider, producers, and consumers as the constitutive agents of a platform, and that platforms have an ecosystem. Papers that address the outcome in their definition of platforms mention the resulting network of producers and consumers [58], the stimulation of value co-creation $[50,60]$, intermediation [25], and economies of scale respectively scope [59]. Jacobides et al. [51] describe the existence of an ecosystem as obviating the need for custom contractual agreements with each partner.

Key distinction: The concept of core and peripheral systems that implies modularity is typical of dominant designs and platforms. Whilst most definitions across dominant designs and platforms draw on outcomes, there is a subtle difference regarding their recognition. In contrast to platforms, dominant designs can only be recognized in retrospect based on subjective guidelines [8]. This counts for earlier definitions (based on a shift from radical to incremental innovation), but also newer definitions based on architecture. Further, dominant designs are the best compromise in a range of applications. Moreover, some platform studies explicitly mention the actors that together comprise a platform ecosystem, something that is not typical of dominant design studies.

\subsection{Positioning}

The analysis showed that most studies across both fields address managers as the problem owners. Much of platform research is written from the viewpoint of a platform leader or platform owner. Notable exceptions are studies on dominant designs that do not include agency of some sort but that implicitly address policy makers based on the choice of variables [22, 23]. Dominant design research predominantly studies the technological design or architecture in some variation as unit of analysis. Sometimes, the technological architecture is studied together with the production process [4], or in combination with the firm $[7,15,57]$. These are mostly studied against the respective industry or product class as a level of analysis [e.g., 6, 8, 15, 56]. Across dominant design studies, we see that the technology and their industry / product class background are central. Most studies on platforms have the platform leader / keystone firm as a unit of analysis [1, 25, 58]. Ecosystem research pays more attention to the locus of technological challenges [40] or the attraction of complementors [59]. Much of platform research takes place at the level of (industry) ecosystems [1, 40, 58, 59].

Both fields' disciplinary backgrounds are multifaceted. Research on platforms draws predominantly on technology / strategic / engineering management and economics. Dominant design is based in the fields of (evolutionary) economics, innovation management, and engineering management.

Regarding empirical contexts, both fields study technological innovation. Research on dominant designs is mostly based in high-tech such as semiconductors or automotive. Platform research is mostly based in ICT, such as mobile apps, PC software, or video games. Noteworthy is the vast numbers of theoretical works in the domain of economic platforms [e.g., 25, 32, 34]. A central theme of dominant design research is the start situation. Many studies assume the existence of several alternative competing technological designs out of which a dominant design is selected [e.g., 6, 8, 15]. Other studies emphasize more the cyclical nature of dominant design selection with experimentation, radical innovation, or incremental innovation based on an existing dominant design as start situation. Platforms research, on the other hand, does not specify such clear starting situations. An implicit assumption of the economics perspective is that different sides of markets exist between whom the platform can mediate [1]. Engineering platforms rest on modularity to cope with complexity. 
Key distinction: Both fields have a focus on technological innovation. Dominant design research studies a technological design against the background of its product class or industry. Platform studies focus mostly on actors (mostly the platform leader, but also complementors) within a platform ecosystem. Empirically, both streams rely on high-tech - dominant design research is based in contexts such as semiconductors or automotive, whereas platforms research mostly draws on ICT contexts. Dominant design research is specific regarding the start situation, assuming alternative technological designs, radical innovation, or an existing dominant design, while a modular architecture is the starting situation of a platform.

\section{Discussion and research agenda}

The analysis of dominant designs and platforms based on the cause-mechanism-output framework suggests that these streams differ most prominently in their causes and underlying mechanisms. Regarding the positioning of the fields, the analysis showed that empirical contexts, as well as units of analysis and levels of analysis distinguish the fields. At the same time, these differences offer potential complementarities.

First, regarding causes, the most significant difference lies in how these phenomena come into being: dominant designs emerge, while platforms result from managerial action. Platforms know a central actor, called platform leader or platform owner, whereas dominant designs are largely non-proprietary, or, to put it differently, emerge as a result of the joint actions by many different firms. Dominant designs often emerge in response to radical innovation and complete an era of ferment. In contrast, little is known on what causes platforms. We expect the following directions for future research: Why and under what conditions are platforms formed? In what way can the literature on dominant designs explain the emergence of a dominant platform?

Second, dominant design and platform research differ in the mechanisms that are at play. Dominant designs know one primary mechanism, namely the selection process. The baseline is that a dominant design emerges out of demand-driven competition in a set of related yet different application contexts, each of which sets slightly different requirements (the dominant design of an airplane is used in very different ranges and for passenger and freight transport). Platform research can be divided into two types of mechanisms: mechanisms lead to the dominance of platforms, and platform-internal coordination mechanisms that coordinate all involved organizations. The former is a mixture of direct and indirect network effects, which overlap with dominant design selection. The latter can be subsumed under platform governance which relates to governance outside of managerial hierarchies. Next to different kinds of mechanisms, it is also evident that the fields differ in duration or timespan of mechanisms. Based on the technology cycle, dominant design thinking acknowledges the come and go of successive dominant designs. This cyclical nature is foreign to platforms thinking which frequently is interested in reaching and maintaining one platform's dominance, while the more cross-sectional actor-centric perspective is alien to the dominant designs thinking. The dominant design perspective is more longitudinal whereas the platforms perspective is more snapshot-like.

In this respect, we see promising research opportunities at the intersection of the long-term evolutionary perspective with the cross-sectional, actor centric view. The cyclical perspective related to the technology cycle that is so common in dominant designs research may lead to new insights in the domain of platforms. For example: Is the technology cycle inherent in dominant design thinking applicable in the context of platforms? We also encourage to study long-term research how systems of complementary products and services in one platform do jointly evolve over time.

For platform managers, it may be especially relevant to relate platform design to different stages of the technology cycle, such as: How does the role and nature of platform design vary across the stages of the technology cycle? Studying platforms through a cyclic lens may require a discussion on levels of analysis at which the technology cycle is applied. As the analysis regarding position revealed, both streams may be complementary on this aspect. Hence: On which level of analysis, such as industry, platform, complement, or focal product, is the technology cycle applicable, and how does it relate to platform design ? We expect distinct research opportunities on different levels. For example, on industrylevel, one may explore the dynamics of platform enabling or platform providing technologies. For instance, are platforms based on pre-paradigmatic enabling technologies such as block chain more ore less fragile than their counterparts based on paradigmatic technologies? As Evans and Schmalensee [62] note, it may be hard to imagine that currently very competitive platforms such as Google or Facebook are subjected to a cyclical pattern and may be eventually overturned. But anecdotal evidence suggests that this is possible, and that platform dominance can be at least successive (e.g., Myspace outcompeted Friendster and later lost to Facebook). Today's platforms my come under threat by distributed platforms relying on blockchain technology [63]. Twoor multi-sided markets may depend on the technology cycle of the focal product that is transacted on their platform. For instance, used car sale platforms such as mobile.de or autotrader.com may depend on the transition 
to powertrains other than internal combustion, with implications for platform design and management. At the complement level, for example, it may help explain the emergence of killer apps

Moreover, recent reviews have focused on indirect network effects in the emergence and growth of platforms, concluding that the complementor perspective is underdeveloped [e.g., 50], and calling for more attention to specific complementary product configurations and mixes [64]. We think that platform research might benefit from a fundamental role of network effects in platform formation, similar to the discussion that Gallagher [8] has sparked in the field of dominant design. Gallagher argues that dominant design selection is largely driven by order-of-magnitude advances in the price-performance-ratio. Network effects may also drive its selection but are not necessary. For example, in 2013, Google acquired the mapping service Waze, which offers largely similar services, except for much stronger user engagement and a culture of mutual helping by reporting accidents, slowdowns, and the like [65]. Hence: To what extent is platform formation driven by direct network effects? When do direct network effects drive platform formation, when is it indirect network effects? As Gallagher [8] argues, a design can be dominant simply because it is the better design. Are there instances where platform success is wrongly ascribed to network effects when it is driven by the price-performance-ratio?

Third, the studied empirical phenomenon is not exactly the same. Dominant design research focusses mostly on standalone complex product architectures in high-tech industries such as semiconductors or automotive, whereas platforms research applies a more systemic perspective, predominantly based in ICT. Systemic approaches to studying innovation such as platform ecosystems (but also innovation systems) often suffer from ambiguities in defining the boundary between system and environment $[66,67]$. This highlights the idea that over time both the platform and the environment jointly evolve. The focus on dominant designs in a product class based on arbitrary thresholds forgoes the complexity arising from connections between organizations but comes at the expense of additional insight. Nevertheless, we suspect that the analytical clarity of this simplification (dominant design in a product class) may help sharpen the boundaries of platform (ecosystem) studies. The other way round, as products are becoming increasingly complex and interconnected [68], it seems inappropriate to bypass the systemic component of technological innovation. This is not to blame dominant design scholars - many central studies in this field were authored long before the widespread adoption of computers, let alone the internet (see Table 1).

\section{Conclusion}

This study addressed the commonalities and differences of dominant designs and platforms. The domains are complementary in the way they deal with aspects of innovations. In the field of IS, innovations are most often technological, not standalone, emerging over time, and enabling a range of applications. Hence, IS may benefit from the integration of both complementary fields.

The contributions are twofold: First, we have developed a framework tailored to the comparison of concepts. It combines aspects from several prior approaches into one framework. Using the framework showed that it serves as a useful protocol for reading and analyzing papers. The multitude of attributes delivers much material for the review but requires the authors to make choices regarding which material to present. It hence provides structure during the review process, making that process more transparent without being too much of a constraint. Second, we applied the framework to compare the concepts of dominant designs and platforms. We elaborated the differences and potential complementarities between dominant designs and platforms, presented as direction for future research. This review adds to a growing literature that intents to take stock, structure, and consolidate recent advances in management research [1, 11, 50, 51, 57], and the comparison of structural metaphors $[8,69]$. This is valuable to scholars and practitioners alike as it facilitates access to the literature and helps bridge the divide between practitioners and scholars.

This study is not without limitations. Clarifying concepts based on theoretical or scientific literature and defining them as precisely as possible is, by nature, a positivist endeavor. Based on recent calls for more synthesis in management research, we believe that his is both necessary and valuable to theory and practice. We think that interpretivist approaches may help understand the situated use of concepts by practitioners and may complement studies similar to ours. As some treat dominant designs and de-facto-standards as synonyms [e.g., 6, 55], we relied on past research [8, 70] for an elaboration of the differences between the two concepts. Nevertheless, the synonymous use of dominant designs and standards may have inferred with the boundaries of this study. Comparing dominant designs and platforms requires identifying the fields' core publications which has been done based on the number of citations as a (dis)qualifier. Relying on an absolute measure of relevance (absolute number of citations) puts older contributions at an advantage over most recent ones. We addressed some of this bias by considering all studies that ISI Web of Science classified as 'highly-cited' which has led to the inclusion of various more recent studies, 
leading to a relatively balanced distribution of the included study over time (by publication year).

\section{Acknowledgements}

This paper was written as part of I AM RRI project that received funding under the EC H2020 SWAFT 122017 programme (grant number 788361).

\section{References}

[1] Gawer, A., "Bridging differing perspectives on technological platforms: Toward an integrative framework", Research Policy 43(7), 2014, pp. 1239-1249.

[2] Thomas, L.D.W., E. Autio, and D.M. Gann, "Architectural Leverage: Putting Platforms in Context”, Academy of Management Perspectives 28(2), 2014, pp. 198-219.

[3] Zhu, F., and M. Iansiti, "Why Some Platforms Thrive and Others Don't”, Harvard Business Review 97(1), 2019, pp. 118-125.

[4] Abernathy, W.J., and J.M. Utterback, "Patterns of Industrial Innovation”, Technology Review 80(7), 1978, pp. 40 47.

[5] Utterback, J.M., and W.J. Abernathy, “A Dynamic Model of Process and Product Innovation”, Omega 3(6), 1975, pp. 639-656.

[6] Anderson, P., and M.L. Tushman, “Technological Discontinuities and Dominant Designs: A Cyclical Model of Technological Change”, Administrative Science Quarterly 35(4), 1990, pp. 604-633.

[7] Christensen, C., F.F. Suarez, and J. Utterback, "Strategies for survival in fast-changing industries”, Management Science 44(12, 2), 1998, pp. S207-S220.

[8] Gallagher, S., "The Complementary Role of Dominant Designs and Industry Standards", IEEE Transactions on Engineering Management 54(2), 2007, pp. 371-379.

[9] Gawer, A., and M.A. Cusumano, "Industry Platforms and Ecosystem Innovation”, Journal of Product Innovation Management 31(3), 2014, pp. 417-433.

[10] Tushman, M.L., and P. Anderson, "Technological Discontinuities and Organizational Environments”, Administrative Science Quarterly 31(3), 1986, pp. 439-465.

[11] Murmann, J.P., and K. Frenken, “Toward a systematic framework for research on dominant designs, technological innovations, and industrial change", Research Policy 35(7), 2006, pp. 925-952.

[12] Pinch, T.J., and W.E. Bijker, "The Social Construction of Facts and Artefacts: or How the Sociology of Science and the Sociology of Technology might Benefit Each Other”, Social Studies of Science 14(3), 1984, pp. 399-441.

[13] Thomke, S., and E. von Hippel, "Customers as Innovators: A New Way to Create Value”, Harvard Business Review 80(4), 2002, pp. 74-85.

[14] Shea, J., "What Do Technology Shocks Do?”, NBER macroeconomics annual 13, 1999, pp. 275-310.

[15] Suarez, F.F., and J. Utterback, "Dominant designs and the survival of firms”, Strategic Management Journal 16(6), 1995, pp. 415-430.

[16] Utterback, J.M., and F.F. Suárez, "Innovation, competition, and industry structure”, Research Policy 22(1), 1993, pp. 1-21.
[17] Khazam, J., and D. Mowery, "The commercialization of RISC: Strategies for the creation of dominant designs”, Research Policy 23(1), 1994, pp. 89-102.

[18] Baum, J.A., H.J. Korn, and S. Kotha, "Dominant designs and population dynamics in telecommunications services: Founding and failure of facsimile transmission service organizations, 1965-1992”, Social Science Research 24(2), 1995, pp. 97-135.

[19] Farrell, J., and G. Saloner, "Installed Base and Compatibility: Innovation, Product Preannouncements, and Predation”, The American Economic Review 76(5), 1986, pp. 940-955.

[20] Katz, M.L., and C. Shapiro, "Technology Adoption in the Presence of Network Externalities”, Journal of Political Economy 94(4), 1986, pp. 822-841.

[21] McIntyre, D.P., and M. Subramaniam, "Strategy in Network Industries: A Review and Research Agenda”, Journal of Management 35(6), 2009, pp. 1494-1517.

[22] David, P.A., "Clio and the Economics of QWERTY”, The American Economic Review 75(2), 1985, pp. 332-337.

[23] Arthur, W.B., "Competing Technologies, Increasing Returns, and Lock-In by Historical Events", The Economic Journal 99(394), 1989, pp. 116-131.

[24] Arthur, W.B., "Increasing Returns and the New World of Business”, Harvard Business Review 74(4), 1996, pp. 100.

[25] Rochet, J.-C., and J. Tirole, "Platform Competition in Two-Sided Markets", Journal of the European Economic Association 1(4), 2003, pp. 990-1029.

[26] Rysman, M., "The Economics of two-sided markets", Journal of Economic Perspectives 23(3), 2009, pp. 125143.

[27] Evans, D.S., “The Antitrust Economics of Multi-Sided Platform Markets”, Yale Journal on Regulation 20, 2003, pp. 59.

[28] Hagiu, A., and J. Wright, “Multi-Sided Platforms”, 2011. http://hbswk.hbs.edu/item/multi-sided-platforms2

[29] Bonardi, J.-P., and R. Durand, "Managing network effects in high-tech markets”, Academy of Management Perspectives 17(4), 2003, pp. 40-52.

[30] Halaburda, H., and Y. Yehezkel, "Focality advantage in platform competition”, Journal of Economics \& Management Strategy 28(1), 2019, pp. 49-59.

[31] Suarez, F.F., and J. Kirtley, "Dethroning an Established Platform”, MIT Sloan Management Review 53(4), 2012, pp. 35-41.

[32] Caillaud, B., and B. Jullien, "Chicken \& Egg: Competition among Intermediation Service Providers”, The RAND Journal of Economics 34(2), 2003, pp. 309-328.

[33] Armstrong, M., "Competition in two-sided markets”, The RAND Journal of Economics 37(3), 2006, pp. 668-691.

[34] Rochet, J.-C., and J. Tirole, "Two-sided markets: a progress report”, The RAND Journal of Economics 37(3), 2006, pp. 645-667.

[35] Wheelwright, S.C., and K.B. Clark, "Creating Project Plans to Focus Product Development”, Harvard Business Review 70(2), 1992, pp. 70-82.

[36] Baldwin, C.Y., and C.J. Woodard, “The Architecture of Platforms: A Unified View”, In A. Gawer, ed., Platforms, markets and innovation. Edward Elgar Publishing, 2009. 
[37] Brusoni, S., “The Limits to Specialization: Problem Solving and Coordination in 'Modular Networks'”, Organization Studies 26(12), 2005, pp. 1885-1907.

[38] Huang, G., X. Zhang, and L. Liang, “Towards integrated optimal configuration of platform products, manufacturing processes, and supply chains”, Journal of Operations Management 23(3-4), 2005, pp. 267-290.

[39] MacDuffie, J.P., “Modularity-as-Property, Modularization-as-Process, and 'Modularity'-as-Frame: Lessons from Product Architecture Initiatives in the Global Automotive Industry: Modularity-as-Property, Modularizationas-Process, and 'Modularity'-as-Frame”, Global Strategy Journal 3(1), 2013, pp. 8-40.

[40] Adner, R., and R. Kapoor, "Value creation in innovation ecosystems: How the structure of technological interdependence affects firm performance in new technology generations”, Strategic Management Journal 31(3), 2010, pp. 306-333.

[41] Boudreau, K.J., “Open Platform Strategies and Innovation: Granting Access vs. Devolving Control”, Management Science 56(10), 2010, pp. 1849-1872.

[42] Nambisan, S., and M. Sawhney, "Orchestration Processes in Network-Centric Innovation: Evidence from the Field", Academy of Management Perspectives 25(3), 2011, pp. 40-57.

[43] Coryn, C.L.S., "The Use and Abuse of Citations as Indicators of Research Quality”, Journal of MultiDisciplinary Evaluation 3(4), 2006, pp. 115-121.

[44] Clarivate, "Web of Science Core Collection Help”, 2018. https://images.webofknowledge.com/images/help/WOS/hs_citation_applications.html

[45] Ginsberg, A., and N. Venkatraman, "Contingency Perspectives of Organizational Strategy: A Critical Review of the Empirical Research", The Academy of Management Review 10(3), 1985, pp. 421-434.

[46] Simsek, Z., "Organizational Ambidexterity: Towards a Multilevel Understanding”, Journal of Management Studies 46(4), 2009, pp. 597-624.

[47] Zahra, S.A., H.J. Sapienza, and P. Davidsson, "Entrepreneurship and Dynamic Capabilities: A Review, Model and Research Agenda*”, Journal of Management Studies 43(4), 2006, pp. 917-955.

[48] Merriam-Webster, "Definition of Natural Disaster", 2020. https://www.merriam-webster.com/dictionary/natu$\mathrm{ral}+$ disaster

[49] Bacharach, S.B., “Organizational Theories: Some Criteria for Evaluation”, Academy of Management Review 14(4), 1989, pp. 21.

[50] McIntyre, D.P., and A. Srinivasan, "Networks, platforms, and strategy: Emerging views and next steps”, Strategic Management Journal 38(1), 2017, pp. 141-160.

[51] Jacobides, M.G., C. Cennamo, and A. Gawer, "Towards a theory of ecosystems”, Strategic Management Journal 39(8), 2018, pp. 2255-2276.

[52] Yurdusev, A.N., “'Level of Analysis' and 'Unit of Analysis': A Case for Distinction”, Millennium: Journal of International Studies 22(1), 1993, pp. 77-88.

[53] Astley, W.G., and A.H. Van de Ven, "Central Perspectives and Debates in Organization Theory", Administrative Science Quarterly 28(2), 1983, pp. 245-273.
[54] Constant II, E.C., The Origins of the Turbojet Revolution, The John Hopkins University Press, Baltimore, 1980.

[55] Schilling, M.A., "Technological Lockout: An Integrative Model of the Economic and Strategic Factors Driving Technology Success and Failure”, Academy of Management Review 23(2), 1998, pp. 267-284.

[56] Henderson, R.M., and K.B. Clark, "Architectural Innovation: The Reconfiguration of Existing Product Technologies and the Failure of Established Firms”, Administrative Science Quarterly 35(1), 1990, pp. 9-30.

[57] Chen, T., L. Qian, and V. Narayanan, "Battle on the Wrong Field? Entrant Type, Dominant Designs, and Technology Exit”, Strategic Management Journal 38(13), 2017, pp. 2579-2598.

[58] Van Alstyne, M.W., G.G. Parker, and S.P. Choudary, "Pipelines, Platforms, and the New Rules of Strategy", Harvard Business Review 94(4), 2016, pp. 54-62.

[59] Boudreau, K.J., "Let a Thousand Flowers Bloom? An Early Look at Large Numbers of Software App Developers and Patterns of Innovation”, Organization Science 23(5, SI), 2012, pp. 1409-1427.

[60] Tiwana, A., B. Konsynski, and A.A. Bush, "Research Commentary-Platform Evolution: Coevolution of Platform Architecture, Governance, and Environmental Dynamics”, Information Systems Research 21(4), 2010, pp. 675-687.

[61] Teece, D.J., "Economics of scope and the scope of the enterprise", Journal of Economic Behavior and Organization 1, 1980, pp. 223-247.

[62] Evans, D.S., and R. Schmalensee, "Why Winner-TakesAll Thinking Doesn't Apply to the Platform Economy”, 2016.

[63] Trabucchi, D., and T. Buganza, "Landlords with no lands: a systematic literature review on hybrid multi-sided platforms and platform thinking”, European Journal of Innovation Management ahead-of-print(ahead-of-print), 2021.

[64] McIntyre, D., A. Srinivasan, A. Afuah, A. Gawer, and T. Kretschmer, "Multi-sided platforms as new organizational forms", Academy of Management Perspectives, 2020, pp. amp.2018.0018.

[65] Cohan, P., "Four Reasons Google Bought Waze”, Forbes, $2013 . \quad$ https://www.forbes.com/sites/petercohan/2013/06/11/four-reasons-for-google-to-buy-waze/

[66] Edquist, C., "The Systems of Innovation Approach and Innovation Policy: An account of the state of the art", (2001), 25.

[67] Kapoor, R., "Ecosystems: broadening the locus of value creation”, Journal of Organization Design 7(1), 2018, pp. 12.

[68] Porter, M.E., and J.E. Heppelmann, "How Smart, Connected Products Are Transforming Competition”, Harvard Business Review 92(11), 2014, pp. 64-88.

[69] Shipilov, A., and F. Burelli, "Don’t Confuse Platforms with Ecosystems”, INSEAD Knowledge, 2020. https://knowledge.insead.edu/blog/insead-blog/dont-confuse-platforms-with-ecosystems-15801

[70] Srinivasan, R., G.L. Lilien, and A. Rangaswamy, “The Emergence of Dominant Designs”, Journal of Marketing 70, 2006, pp. 1-17. 